\title{
LA FUNCIÓN SUSTANTIVA DEL PARTICIPIO DE PASADO EN ESPAÑOL
}

\begin{abstract}
Resumen. El objetivo básico de este estudio es demostrar cómo la semántica, el conocimiento del mundo y la cognición influyen en las unidades léxicas, en nuestro caso en las formas nominalizadas del participio de pasado español tanto regular, como irregular. A partir del emparejamiento forma / significado de las formas del participio se analizan los aspectos más significativos del funcionamiento de la recategorización de este sustantivo en su uso pragmático, con la diferencia regularidad / irregularidad, como incidencia en su comportamiento léxico-semántico y en la consiguiente gramaticalización en función del contexto.
\end{abstract}

Palabras clave: recategorización, cognición, pragmática, forma, significado.

\section{Introducción}

Con este estudio pretendemos ofrecer principalmente un enfoque más comprensivo y explicativo del participio de pasado regular e irregular, dados los distintos cambios gramaticales que estas formas presentan en función de su uso pragmático. Dentro de la morfología será de gran utilidad partir de su formación, que ya gramáticos del siglo XVII como Miranda, Oudin, Smith, Franciosini y Des Roziers (Medina Montero, 2015: 119) entendían que los verbos de la primera y tercera conjugación formaban el participio cambiando la ' $r$ ' del infinitivo en -do, una explicación simple, que a la larga servirá de fulcro para entender en parte la alta frecuencia de formas regulares que presentan estos cambios gramaticales, por otra parte muy limitada en los irregulares. De ahí que esta segmentación aparezca mentalmente interpretada como una asociación que comparte los significados de la acción verbal con la terminación en

\footnotetext{
* Università Ca' Foscari di Venezia.
} 
-do del hecho realizado que corresponde al participio, transformándose en una constante de este participio en forma nominal.

Nos hemos centrado, pues, en las interacciones entre este elemento léxico y su uso como centro que explica las distintas recategorizaciones dentro de la textura gramatical del español, teniendo siempre presente la importancia de la amplia conceptualización implícita en la unidad verbal y que, en el caso que nos ocupa, se aplicará a la función de nombre dentro del proceso de gramaticalización.

\section{El verbo como proceso}

La idea de que el lenguaje es un inventario de unidades lingüísticas convencionales (Langacker, 1987: 159) nos aparece muy ligada al concepto de unidad verbal, debido principalmente a que debemos entender esta como un proceso en continua evolución. Con respecto al participio de pasado referido a su función de sustantivo de gran frecuencia con formas regulares, el español, a diferencia de otras lenguas latinas, presenta formas que son el resultado de convencionalizaciones que con el uso pragmático conllevan inferencias muy concretas, en algunos casosllegan a ser metáforas muy particulares con respecto a su significado original, manifestaciones del carácter combinatorio del pensamiento. Estas formaciones en participio, por otra parte, pueden considerarse como formas parcialmente emancipadas (Marsà, 1986: 203), es decir, que su transformación en otra categoría gramatical dependerá fundamentalmente de las combinaciones que se formen con él, ya que sería un error estudiarla como forma aislada. De esta manera podemos analizar el participio irregular harto en función adverbial a partir de un proceso de recategorización que va del participio al adjetivo, y de este al adverbio, de uso muy específico en el español europeo ${ }^{1}$ con el significado de 'bastante' o 'demasiado' con adjetivos que implican dificultad, como son los casos de los sintagmas harto arriesgado, harto complicado, o harto dificil, y cuyo uso se documenta por lo menos desde el S. XVI, específicamente señalaremos la forma femenina en el segundo Lazarillo 'entramos dentro con harta poca resistencia' e incluso su empleo como sustantivo, hoy en desuso, en el sentido de 'hartura' en Serrana de la Vera de Vélez de Guevara en 'tal vez suele agradar una

${ }^{1}$ Señalamos su uso general en Bolivia, Chile y México, el uso en Chile ya había sido constatado por Corominas y Pascual (1980: 323). 
villana / como tosco manjar, que por antojos / da el harto del faysán al apetito (Corominas y Pascual, 1980: 323).

La emancipación de esta forma nominal de verbo, por otra parte, la podemos explicar con el análisis de construcciones nominales cuyas imágenes están presentes en el pensamiento como proyección inmediata de la mente. Podrían ser, entre otros, los casos de formas como certificado, helado, juzgado, partido, pescado o refugiado, que efectivamente son las imágenes basadas directamente en las representaciones neuronales que se organizan topográficamente donde llegan las percepciones visivas, auditivas, etc. (Damasio, 1995: 20), que el espacio mental de estos participios como sustantivos cubre en frases como Estamos esperando los certificados, En Italia hay muy buenos helados, Hoy tengo que ir otra vez al juzgado, Siempre toma vino con el pescado o Sigue aumentando el número de refugiados, respectivamente. El espacio mental es más reducido en su uso adjetival con sentido pasivo en Todavía no me ha llegado la carta certificada, No le gusta la fruta helada, Se trata de un trabajo juzgado por una comisión de expertos, Ha puesto en la mesa el pan partido, Tenemos que cocinar el calamar pescado, Las mujeres refugiadas fueron trasladadas a un centro de asistencia, siendo posible al mismo tiempo que el hablante llegue a omitir su uso, ya que en realidad estos participios se presentan como especificaciones de los sustantivos a los que acompañan.

\section{El participio de pasado como sustantivo}

El concepto de que el participio forma parte del verbo y del sustantivo, como ya afirmaba Dionisio de Tracia y reiteraba Antonio de Nebrija (1980: 191) en su Gramática de la Lengua Castellana explicando que de esta doble partición procede su nombre, es la primera cuestión que queremos presentar al analizar esta forma no personal del verbo, ya que en ambas funciones un análisis de sus características se hace necesario dado su particular empleo en español con respecto a otras lenguas.

A lo largo de los siglos se ha venido estudiando esta forma no personal a nivel práctico, concretamente en lo referente a su tipología y formación, dejando a un lado cualquier aspecto teórico. Sostenemos, pues, que la base teórica de su estudio tiene que ir ligada estrechamente a una autonomía bien definida, como ya era constatado por muchos tratadistas de los Siglos de Oro y que vemos en el uso de muchos participios que funcionan como auténticos sustantivos, sin pensar en ningún caso que son formas simplificadas de los sintagmas nominales de los que derivan. Entre otros 
muchos, estos podrían ser los casos de resfriado (un resfriado de aúpa), salvado (salvado de trigo), surtido (un surtido de quesos) donde podemos observar que en su función sustantiva sus respectivos significados se alejan tanto formal como semánticamente de los sintagmas de los que formaban parte $\mathrm{y}$, en consecuencia, de sus significados originales, pensemos en construcciones como 'una persona resfriada', 'un rehén salvado' o 'galletas surtidas' respectivamente. En la función sustantiva el concepto de resfriado lo entendemos como el de 'catarro', es decir, 'flujo o destilación procedente de las membranas mucosas, especialmente las nasales', con salvado pensamos en 'la cáscara del grano de los cereales desmenuzada por la molienda' y por surtido nos referiremos a 'la mezcla de diversas clases'. Observamos, por lo tanto, que se han formado unos sustantivos participiales cuyos significados no solo se alejan de las bases de las que proceden respectivamente, 'resfriar' (enfriar), 'salvar' (librar) y 'surtir' (proporcionar), sino que al mismo tiempo son los núcleos de la larga serie de construcciones que generan. En el proceso de recategorización de estos participios llega a ser muy significativo el uso que a lo largo del tiempo estas formas han ido adquiriendo, diríamos que de forma paralela a la de sus sinónimos, como resultado de un proceso de creatividad léxica que surge de la relación de la mente con lo externo. Así con resfriado existe una estrecha conexión con el primitivo 'catarro' (de acatarrar) ${ }^{2}$ como podemos ver en el campo combinatorio que forman, pues ambos sustantivos comparten verbos como 'coger', 'contagiar', 'curar(se)', 'pegar' o 'pillar' en la colocación verbo-sustantivo; con salvado tenemos un uso específico que corresponde al afrecho en colocaciones del tipo S-Prep.-S como 'salvado de trigo', 'salvado de avena', etc.; del mismo modo que surtido en 'surtido de lápices', 'surtido de quesos', etc.

En función sustantiva señalaremos un complejo grupo de participios de formas regulares con estas características: acabado, allegado, arado, barrido, batido / batida, calzado / calzada, cercado, certificado, clasificado, cocido, colmado, concentrado, decorado, defendido, delegado, denunciado, desagradecido, desamparado, desaparecido, descampado, desenganchado, desfogado, desocupado, duplicado, embalado, embolado, empapelado, empaquetado, emparedado, encargado, encendido, encerado, enchufado, encintado, encogido, enganchado, entoldado, entretenido, enunciado, facturado, filtrado, fingido / fingida, fumigado, galopado, ganado, garrapiñado / garrapiñada, grabado, goleado / goleada, gozado I gozada, graduado, granizado / granizada, granulado, grapado, guiñado, helado / helada, herido / herida, hinchado / hinchada, iluminado, juzgado, lanzado,

${ }^{2}$ El primer documento en el que encontramos este lema es la Crónica de Don Juan de 1460 (Corominas y Pascual, 1980: 922). 
lechado, legado, librado, licenciado, malentendido, mercado, mirado, montado, parado, pasado / pasada, pegado, peinado, pelado, pescado, rayado, rebotado, recaido / recaida, recorrido, refugiado, regado, remontado / remontada, reservado, retrasado, rotulado, sacudido / sacudida, salido / salida, sellado, sembrado, tejado, tendido, tocado; y de irregulares como son, entre otros, los casos de: escrito, fijo, impreso, puesto, revuelto, roto, sujeto.

\section{De la acción a la concreción}

La transitividad de la acción explica la notable presencia de la función sustantiva en sustantivos formados directamente a partir de participios en español ${ }^{3}$, a diferencia de otras lenguas latinas, a lo que tenemos que añadir el sentido extensivo con la formación de sustantivos femeninos, como bien podemos observar en ejemplos como el batido / la batida, el calzado / la calzada y el pintado / la pintada, todo lo cual nos hace pensar en una extensión metafórica que se concretiza primero en un sustantivo masculino para cubrir posteriormente un área más extensa en la forma femenina, ya que el significado de la forma masculina, a diferencia de la femenina, se identifica más con el del verbo original como tenemos en batido con el significado de 'mezcla batida de claras, yemas o huevos completos' en su primera acepción, y el de 'bebida que se prepara triturando y mezclando con una batidora diversos ingredientes, especialmente leche, fruta o helado'; en la segunda; ambas acepciones en estrecha relación con lo expresado por la unidad verbal, es decir, la idea referida a una sustancia, especialmente si es líquido, de mezclarla o agitarla hasta que se condense, se disuelva o se licue; por el contrario la forma femenina batida -cuyo género lo analizamos como una simplificación del sintagma correspondiente 'una caza batida'- aparece con la idea de 'reconocimiento o registro de una lugar persiguiendo un objetivo' como podemos encontrar en frases del tipo Los cazadores dieron una batida por el monte apenas llegaron o La policía sorprendió a los traficantes con una batida por todo el barrio. En ambas frases este significado es una extensión de la locución verbal dar una batida con el significado de 'acción de batir el monte para que salga la caza' (Corominas y Pascual, 1980: 545), cuya presencia se constata en 1644. Por el contrario, la datación del participio masculino en función sustantiva resulta ser más reciente, concretamente hablamos de finales del siglo XIX, si bien la

${ }^{3}$ Como botón de muestra podemos citar los ejemplos de juzgado, tribunal (fr.), tribunale (it.), tribunal (port.); o ganado, bétail (fr.), bestiame (it.), gado (port.). 
función adjetiva es paralela en el tiempo a su correspondiente verbal, es decir, durante el siglo XIII, empleado por Berceo al mismo tiempo que la forma antigua 'bater'. Hablaremos, pues, de un primer desarrollo paralelo al del infinitivo en la forma masculina y de una proyección posterior como metáfora en la forma femenina.

Esta doble función sustantiva es la que encontramos igualmente en el par calzado / calzada, donde igualmente el concepto de calzado se explica en relación con la idea de 'calzar', entendida como 'cubrir el pie con todo lo que sirve' y de ahí el participio en función sustantiva con la idea de lo que suele entenderse por zapato; calzada llega a tener su origen en 'el camino empedrado, que se levanta regularmente en algún lugar pantanoso para seguridad de los pasajeros' (RAE, 1976: 80), de donde pasa a ser la calzada o calle actual, ya que en realidad se trata de 'calzar el camino'. Esta acepción femenina es la que nos sirve igualmente para diferenciar el par pintado / pintada, donde con pintado ${ }^{4}$ nos referimos al resultado de cubrir con color una superficie, mientras que con la formación pintada hablaremos de algo concreto como 'la figura o letrero generalmente de contenido político o social, pintada o escrita en algún lugar'.

Ocurre que en español del mismo modo encontraremos otros muchos participios regulares en las que solo la forma masculina funciona como sustantivo indicando el conjunto del proceso que marca la acción verbal, pensamos en participios como decorado, empapelado, fumigado, recorrido, etc., al igual que participios que solo nominalizan las forma femenina ${ }^{5}$ con un significado muy específico como podemos ver en 'recaída' con la idea de 'empeoramiento de una enfermedad de la que una persona estaba mejorando'.

\section{La función sustantiva de las formas irregulares}

La relación forma / función presenta en el caso de los verbos con doble participio la particularidad de que las formas irregulares en líneas generales corresponden a una centralización semántica muy definida a nivel cognitivo. De hecho, si pensamos en el término impreso la idea que nos viene a la mente es la del formulario que hay que rellenar para realizar un trámite, del mismo modo que frito lo conectaremos con

${ }^{4}$ Señalamos aquí que muchos sustantivos participiales con esta misma formación han sido sustituidos por sustantivos de nueva creación.

${ }^{5}$ Hablaremos de casos muy concretos como los de goleada, gozada, pasada, pegada, torcida, entre otros. 
el resultado de cocinar al fuego un alimento o manifiesto con el escrito político dirigido a la opinión pública con la intención de exponer una ideología o un programa. De ahí que consideremos los participios irregulares como formas emancipadas o periféricas de la idea central que todo verbo presenta como proceso con una marcada recategorización como sustantivo (Sarmiento, 1997: 213).

La morfología de las formas irregulares se caracteriza por las terminaciones -cho, -so y -to como podemos encontrar en dicho, impreso y escrito.

Entre otros, destacaremos los dobles participios siguientes:

ayunar
compeler
convencer
expresar
fijar
freír
hartar
imprimir
incluir
injerir
manifestar
poseer
prender
recluir
salvar
soltar
sujetar
suspender
sustituir
teñir
torcer
vaciar

ayunado
compelido
convencido
expresado
fijado
freído
hartado
imprimido
incluido
injerido
manifestado
poseído
prendido
recluido
salvado
soltado
sujetado
suspendido
sustituido
teñido
torcido
vaciado

ayuno
compulso
convicto
expreso
fijo
frito
harto
impreso
incluso
injerto
manifiesto
poseso
preso
recluso
salvo
suelto
sujeto
suspenso
sustituto
tinto
tuerto
vacío

Señalamos en este doble participio el uso de la forma regular en los tiempos compuestos del verbo y como adjetivo, y de la irregular como adjetivo y, en algunos casos, como participio.

Debemos observar en esta doble formación de las formas de participio el cambio de matiz o incluso de significado existente a causa del paso de la acción al resultado como podemos ver entre Otra vez he suspendido el examen y Estoy suspenso, pues en el primer caso nos referimos a la acción de suspender el examen, mientras que en el segundo se trata del resultado de esa acción. Es muy frecuente, por otra parte, incluso un cambio de significado, que entendemos como una clara proyección del original como ocurre con recluido y recluso, en Se ha recluido para sacar esas oposiciones y Se han vuelto a escapar unos reclusos de esa cárcel da máxima 
seguridad, pues presentamos el hecho de forma activa y pasiva que, a nivel semántico interpretaremos como 'dedicarse plenamente a una actividad' y como 'preso', respectivamente.

Como cambio de categoría gramatical destacamos la frecuencia del paso de adjetivo a sustantivo como ocurre con formas como preso, manifiesto, sustituto o vacío, entre otras, donde observaremos incluso una extensión del significado original, como podemos ver en La huelga de presos ha tenido una gran repercusión, Toda la universidad estaba llena de manifiestos, Hoy ha venido un sustituto a dar clase de Química y Después de la muerte del padre se creó un gran vacío en la familia o el de adjetivo a preposición como es el caso de "salvo" en Estuvimos todos presentes en el homenaje, salvo tú; con el valor preposicional, caso extraño es el cambio de 'incluso', ya que como adjetivo apenas aparece documentado a pesar de que viene indicado como tal en distintos diccionarios, añadimos sin ningún tipo de ejemplificación, pero como adverbio lo podemos encontrar en frases como Aparece por el trabajo incluso los sábados.

En los verbos con participio irregular como forma única, pensemos entre otros en escrito, hecho o puesto, se mantiene igualmente la relación semántica con el verbo original, con una extensión metafórica significativa en lo que se refiere a las combinaciones que estas formas generan.

\section{Conclusiones}

Los cambios semánticos y morfológicos que las formas de participio han ido adquiriendo a lo largo de los siglos en español constituyen aspectos importantes en el proceso de recategorización a que dan lugar. Para acercarnos a la vasta complejidad semántica que originan, se ha hecho necesario, pues, el análisis en su uso pragmático, recurriendo en la medida de lo posible a situaciones definidas, dejando entrever en todo caso los contrastes más significativos en relación con otras lenguas desde el funcionamiento en español.

Nuestro objetivo ha sido dar a entender los mecanismos mentales que determinan su uso y la variedad léxico-semántica que la lengua española ofrece en este aspecto, sin olvidar la necesidad de una sistematización de estas formas no personales tanto a nivel morfosintáctico como léxicosemántico con fines didácticos y traductológicos. 


\section{Bibliografía}

COROMINAS, J. y PASCUAL, J. A. (1980). Diccionario crítico etimológico castellano hispánico. Madrid: Gredos.

DAMASIO, A. (1995). L'errore di Cartesio. Emozione, ragione e cervello umano. Milano: Adelphi.

LANGACKER, R. (1987). Foundations of cognitive grammar. Stanford (California): Stanford University Press.

MARSÀ, F. (1986). Diccionario normativo y guía práctica de la lengua española. Barcelona: Ariel.

MEDINA MONTERO, J. F. (2015). El verbo, el participio y las clases de palabras invariables en las gramáticas de español para extranjeros de los siglos XVI y XVII. Firenze: Olschki.

NEBRIJA, A. DE (1980). Gramática de la Lengua Castellana. Madrid: Editora Nacional.

RAE (1976). Diccionario de Autoridades. Madrid: Gredos.

RAE (2009). Nueva Gramática de la lengua española. Madrid: Espasa.

SARMIENTO, R. (1997). Manual de corrección gramatical y de estilo. Madrid: SGEL. 